\title{
Identifikasi Aksesibilitas Angkutan Umum Dan Terminal Kawasan Metropolitan Sarbagita
}

\author{
A. Soimun*1, Anggun Prima Gilang Rupaka ${ }^{2}$, Ni Wayan Putu Sueni ${ }^{3}$, \\ Hendrialdi ${ }^{4}$ \\ ${ }^{12}$ Manajemen Logistik, Politeknik Transportasi Darat Bali \\ ${ }^{3}$ Manajemen Transportasi Jalan, Politeknik Transportasi Darat Bali \\ ${ }^{4}$ Teknologi Nautika, Politeknik Pelayaran Sumatera Barat \\ E-mail: *soimun@poltradabali.ac.id
}

Received 09-04-2021; Reviewed 07-05-2021; Accepted 23-05-2021-05-23

Journal Homepage: http://ktj.pktj.ac.id/index.php/ktj

DOI: $10.46447 / \mathrm{ktj} . v 8 i 1.309$

\begin{abstract}
Abstrak
Pemerintah Indonesia melalui kementerian pekerjaan umum telah menetapkan beberapa Kawasan metropolitan yang berkembang diantaranya Kawasan SARBAGITA. Kawasan tersebut meliputi Kota Denpasar sebagai pusat perekonomian dan daerah penyokongnya Kabupaten Badung, Kabupaten Gianyar, dan Kabupaten Tabanan. Tulisan ini bertujuan untuk menjelaskan dan menganalisis kelayakan aksesibilitas angkutan umum dikawasan metropolitan SARBAGITA untuk mendukung aktifitas masyarakat sekitar. Dari segi aksesibilitas angkutan umum memiliki fasilitas penunjang diantaranya terminal, halte, dan jalan yang mana dari tiga fasilitas tersebut merupakan simpul transportasi yang perlu diperhatikan dalam evaluasi. Hasil dari evaluasi didapatkan fasilitas aksesibilitas angkutan umum dikawasan SARBAGITA sudah cukup baik seperti fasilitas terminal tipe A sampai $C$. lokasi terminal sudah sesuai dengan tata guna lahan di Kawasan SARBAGITA. Yang perlu ditingkatkan adalah fasilitas halte di sepanjang jalan seperti fisik halte dan rambu rambu yang jelas, agar masyarakat mudah untuk menjangkau dan mau menggunakan angkutan umum. Hal ini sangat dibutuhkan agar meningkatkan kemauan masyarakat untuk menggunakan moda angkutan umum dan angkutan umum mampu menjadi moda andalan dalam mendukung pariwisata di Kawasan SARABGITA.
\end{abstract}

Kata kunci: Aksesibilitas, Angkutanumum, Terminal, Sarbagita

\section{PENDAHULUAN}

Dalam kehidupan bermasyarakat transportasi memiliki peran yang sangat besar dalam menentukan kemajuan suatu bangsa dan negara, peranan transportasi merupakan daya saing bangsa sebagai sarana untuk melakukan interaksi dalam setiap aktivitas yang dalam hal ini bagaimana suatu bangsa mampu mengelola system transportasi yang handal, (Putra, 2016). Transportasi jalan raya di era yang semakin modern ini merupakan salah satu masalah yang penting untuk diperhatikan. Dengan pesatnya perkembangan ekonomi dan urbanisasi, jumlah kendaraan bermotor perkotaan terus meningkat (Oktopianto et al., 2021).

Transportasi juga memegang peranan sangat penting dalam hal perkembangan pembangunan ekonomi dan pembangunan non ekonomi (Vukan, 1981). Contohnya keberhasilan transportasi akan sangat berdampak terhadap 
kenaikan ekonomi suatu daerah. Pentingnya transportasi tersebut tercermin pada semakin meningkatnya kebutuhan akan jasa angkutan bagi mobilitas orang serta barang sebagai akibat meningkatnya perkembangan penduduk dan pengembangan pemukiman yang semakin luas terutama di Kawasan strategis (Wulandari C \& Sudiana, 2018).

Untuk meningkatkan kemajuan ekonomi disuatu Kawasan perlu hal nya memikirkan dengan matang pembangunan simpul transportasi yang handal, begitu juga dengan Kawasan SARBAGITA (Putrayasa \& Maharani, 2014). Menurut ketetapan peraturan Perpres no 45 tahun 2011 tentang tentang Rencana Tata Ruang Kawasan Perkotaan Denpasar, Badung, Gianyar Dan Tabanan dimana Kawasan tesebut disingkat menjadi Kawasan SARBAGITA.

Pembentukan kawasan SARBAGITA diawali dengan adanya pengembangan sistem perkotaan di Provinsi Bali, yang disahkan dalam Peraturan Daerah Provinsi Bali Nomor 4 Tahun 1996 tentang RTRW Provinsi Bali, Bagian Ketiga Pasal 2. Dengan terbentuknya pengembangan sistem kota-kota Provinsi Bali menurut sistem dan fungsi kota dapat dibagi menjadi 4 (empat) sistem kota yaitu, Kabupaten Gianyar, Kota Denpasar, Kabupaten Badung dan Kabupaten Tabanan. seperti pada gambar. Berdasarkan Kementerian PUPR, luas wilayah Kawasan Metropolitan SARBAGITA adalah 723,99 km2.

Dalam perencanaan Kawasan yang berintegrasi dengan baik perlu diperhatikan aksesibilitas transportasi yang sangat dibutuhkan diantaranya angkutan umum, Terminal dan jalan. Dalam perancangan angkutan umum perlu diperhatikan konektivitas dan tingkat aksesibilitas moda tersebut (Putu A. S, 2010). Angkutan umum diselenggarakan dalam upaya memenuhi kebutuhan angkutan yang selamat, aman nyaman dan terjangkau. Ketersediaan angkutan umum merupakan tanggung jawab dari pemerintah sebagai upaya peningkatan aksesibilitas dan konektifitas antar wilayah. Pelayanan angkutan multimoda harus terpadu secara sistem dan mendapat izin dari pemerintah (UU No 22 Tahun 2009).

Dalam prakteknya mobilitas masyarakat dikawasan sangat perlu didukung oleh aksesibilitas transportasi yang memadai. Ukuran dari aksesibilitas yang baik sangat dipengaruhi oleh 4 komponen utama diantaranya: 1 . Komponen transport mengacu pada kecepatan, biaya dan waktu perjalanan. 2. Komponen penggunaan lahan mengacu pada distribusi dan jumlah perjalanan yang dilakukan. 3. Komponen sementara mengacu pada periode waktu yang dipakai selama perjalanan. 4 . Komponen individu mengacu pada pendapatan dan tingkat Pendidikan pelaku perjalanan (Geurs \& Wee,2004).

Menurut (Suthanaya, 2009) aksesibilitas menjadi salah satu bagian yang memiliki peran dalam system jaringan transportasi. Aksesibilitas juga berperan dalam meramalkan dampak lalu lintas dan kebijakan transportasi yang ada di lingkungan sekitar. Adapun aksesibilitas sering kali dikaitkan dengan 3 variabel utama yaitu jarak, waktu tempuh dan biaya perjalanan (Black, J \& Conroy, M,1977).

Kawasan kota metropolitan SARBAGITA sendiri memiliki sudah memiliki fasilitas aksesibilitas yang mendukung pergerakan masyarakat diantaranya beberapa terminal 1 Terminal Tipe A, 2 Terminal Tipe B dan beberapa terminal Tipe C (UU No 22 Tahun 2009). 
Dengan permasalahan aksesibilitas yang perlu diperhatikan dalam mobilitas masyarakat disuatu Kawasan maka perlu di lakukan evaluasi aksesibilitas di Kawasan SARBAGITA untuk mengetahui apakah kondisi pelayanan angkutan umum sudah sesuai dengan peraturan dan fungsinya dengan baik (Adisasmita, 2014). Tujuan dari penulisan ini adalah mmberikan gambaran kondisi aksesibilitas di Kawasan SARBAGITA serta usulan kepada pemerintah provinsi Bali untuk selalu memperhatikan pelayanan yang diberikan kepada masyarakat sekitar.

\section{METODE}

Metodologi penelitian yang digunakan pada penelitian ini menggunakan statistic deskriptif. Data yang digunakan dalam penelitian ini ada 2 tahapan yang dilakukan diantaranya : data sekunder dilakukan dengan meminta data kepada dinas perhubungan yang berada di Kawasan SARBAGITA. Data yang didapat merupakan data mentah dimana menjelaskan tentang letak terminal, luasan dan fasilitas aksesibiitas yang ada di terminal dan jalan. Data primer dilakukan observasi lapangan untuk mendapatkan informasi terkait kondisi terminal dikawasan SARBAGITA. survey langsung juga untuk mendapatkan informasi fasilitas fasilitas tambahan yang ada di terminal, kondisi lingkungan dan system manajemen yang ada diterminal. Dokumentasi lapangan digunakan untuk menggambarkan kondisi lapangan. Data yang diperoleh dari 2 sumber tersebut diolah menjadi data kualitatif dan di bandingkan dengan peraturan yang ada.

Lokasi penelitian dilakukan di Kawasan SARBAGITA provinsi Bali. SARBAGITA merupakan Kawasan yang akan dikembangkan menjadi Kawasan Kota Metropolitan City. Menurut Data BPS 2020 Luas kawasan Metropolitan Sarbagita yaitu sebesar $723.97 \mathrm{~km}^{2}$. Jumlah penduduk Metropolitan Sarbagita pada tahun 2020 yaitu sebanyak 2.128,58 jiwa (BPS Denpasar, Badung, Gianyar dan Tabanan Dalam Angka 2020). Waktu penelitian dilakukan pada bulan September - November 2020.

\section{HASIL DAN PEMBAHASAN}

\section{Kondisi Umum Kawasan SARBAGITA}

Kawasan Metropolitan Sarbagita telah ditetapkan berdasarkan Peraturan Presiden No. 45 Tahun 2011 tentang Rencana Tata Ruang Kawasan Perkotaan Denpasar, Badung, Gianyar, dan Tabanan (Sarbagita). Perpres tersebut mengatur mengenai peran dan fungsi Rencana Tata Ruang Kawasan Perkotaan Sarbagita, cakupan, tujuan, kebijakan, strategi, rencana struktur ruang, rencana pola ruang, arahan pemanfaatan ruang, dan arahan pengendalian pemanfaatan ruang, serta peran masyarakat dalam penataan ruang Kawasan Perkotaan Sarbagita. Selain itu, Perpres juga memuat Peta Rencana Struktur Ruang Kawasan Perkotaan Sarbagita, Peta Rencana Pola Ruang Kawasan Perkotaan Sarbagita, dan Indikasi Program Utama Lima Tahunan Arahan Pemanfaatan Ruang Kawasan Perkotaan Sarbagita seperti pada gambar 2. 


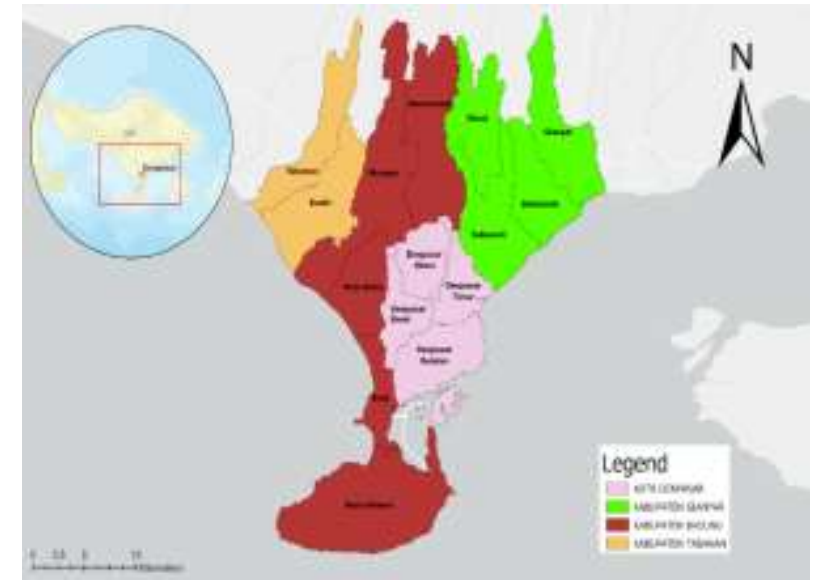

Gambar 2. Kawasan Metroplitan SARBAGITA

\section{Aksesibilitas Angkutan Kota Kawasan SARBAGITA}

Aksesibilitas suatu Kawasan sangat bergantung pada fasilitas Kawasan tersebut dalam membangun dan merencanakan tata guna lahan. Aksesibilitas merupakan ukuran kenyamanan atau kemudahan dalam berinteraksi satu sama lain dengan mudah untuk dicapai melalu sistem jaringan transportasi yang handal. Setiap lokasi memiliki tingkat aksesibilitas yang berbeda beda dikarenakan perbedaan wilayah seperti batas wilayah desa, kecamatan, dan kabupaten.

Suatu Kawasan akan bersinergi dalam perencanaan dan pembangunan tata guna lahan apabila di jadikan satu Kawasan dalam perencanaan yang baik seperti hal nya SARBAGITA di propinsi Bali. Aksesibilitas pada Kawasan sarbagita terdiri dari fasilitas Jalan, jarak lokasi terminal dengan Kawasan penduduk, waktu tempuh perjalanan menuju pusat kota, waktu tunggu angkutan kota, dan waktu perjalanan angkutan kota tersebut.

Aksesibilitas dari sistem angkutan kota Kawasan SARBAGITA nantinya diharapkan mampu untuk menarik minat masyarakat untuk melakukan perjalanan menggunakan angkutan umum. Aksesibilitas yang diharapkan oleh masyarakat Kawasan SARBAGITA yang didapatkan melalui survey wawancara adalah

a. Dari segi pelayanan angkutan umum yang mencakup tentang keamanan, kenyamanan ketersediaan sarana dan prasarana, ketepatan jadwal, jarak antar angkutan umum dan pemberlakukan tarif yang sesuai.

b. Tempat naik dan turun angkutan umum diperbanyak jumlah dan kualitasnya diperhatikan seperti tempat duduk untuk menunggu, perlindungan dari sinar matahari dan hujan.

c. Keseriusan dalam mengelola angkutan umum adanya kepastian jadwal waktu (kedatangan dan keberangkatan serta dapat di pantau melalui aplikasi $\mathrm{hp}$ ) mudah diakses, mobilitas tinggi, terjangkau, ramah lingkungan. serta angkutan umum di wilayah SARBAGITA harus juga dapat mendukung pariwisata Bali sebagai salah satu destinasi wisata dunia.

d. Terintegrasi angkutan umum dari terminal sampai ke halte terdekat untuk dimana penumpang dapat mengakses lokasi halte dan angkutan lanjutan, perlu diperhatikan juga lokasi halte dengan pusat keramaian dan fasilitas umum sehingga memudahkan untuk dicapai dengan jalan kaki. Angkutan sarbagita dibuat senyaman mungkin dan bersahabat untuk semua kalangan. 
Dari segi ekonomi dibuat seefisien mungkin agar dapat di jangkau semua kalangan.

e. Pemerintah daerah selaku penyedia dan pengawasan melakukan promosi penggunaan angkutan umum untuk melakukan perjalanan dikawasan SARBAGITA untuk mengurangi kemacetan di jalan pada jam puncak.

\section{Jalan Provinsi Kawasan SARBAGITA}

Rencana sistem jaringan prasarana Kawasan Perkotaan Sarbagita meliputi sistem jaringan yang meliputi transportasi, energi, telekomunikasi, sumber daya air, dan prasarana perkotaan. Jaringan transportasi yang harus mulai dikembangkan adalah jaringan jalan untuk menunjang kegiatan masyarakat dalam melakukan aktifitas. Jaringan jalan provinsi Bali bisa dilihat seperti pada gambar 3.

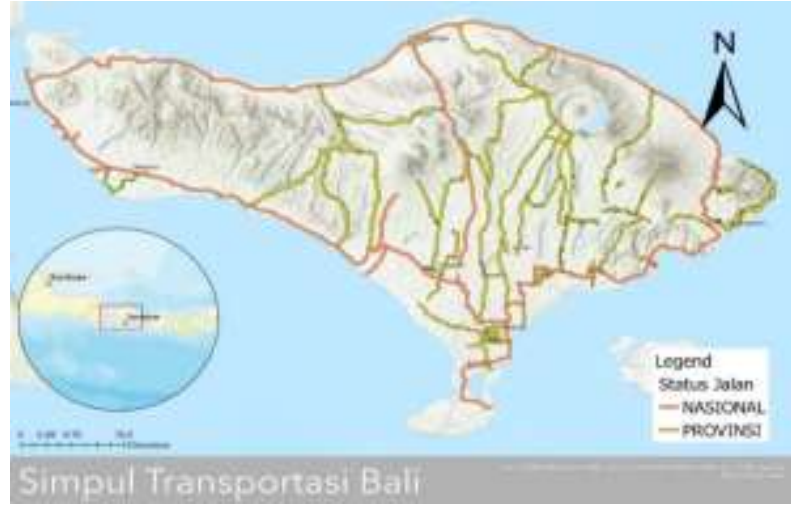

Gambar 3. Jalan Provinsi dan Jalan Nasional di Bali (Sumber: Google Maps)

Untuk menunjang kegiatan Kawasan kota metropolitan juga harus diperhatikan status jalan menurut kewenangan untuk bisa melakukan perbaikan dan pemenuhan fasilitas jalan. Berikut tabel Panjang jalan menurut kabupaten kota Kawasan SARBAGITA tahun 2019.

Tabel 2. Panjang Jalan Menurut Kabupaten/Kota dan Tingkat Kewenangan Pemerintahan di Provinsi Bali Kawasan SARBAGITA Keadaan Akhir Tahun 2019

\begin{tabular}{|c|c|c|c|c|}
\hline \multirow[b]{2}{*}{$\begin{array}{c}\text { Kabupaten } \\
\text { / Kota }\end{array}$} & \multicolumn{4}{|c|}{ Status Jalan (Km) } \\
\hline & $\begin{array}{c}\text { Jalan } \\
\text { Negara }\end{array}$ & $\begin{array}{c}\text { Jalan } \\
\text { Provinsi }\end{array}$ & $\begin{array}{c}\text { Jalan } \\
\text { Kabupate } \\
\text { n/Kota }\end{array}$ & Jumlah \\
\hline Tabanan & 65.88 & 136.72 & 863.22 & 1065.82 \\
\hline Badung & 63.47 & 61.18 & 663.41 & 788.06 \\
\hline Gianyar & 64.33 & 85.52 & 515.24 & 665.09 \\
\hline Denpasar & 49.89 & 43.33 & 486.09 & 579.31 \\
\hline $\begin{array}{l}\text { Jumlah } \\
\text { Total : }\end{array}$ & 243.57 & 326.75 & 2527.96 & 3098.28 \\
\hline
\end{tabular}




\section{Terminal Penumpang Kawasan SARBAGITA}

Di propinsi Bali khususnya Kawasan SARBAGITA ada beberapa terminal yang berfungsi sebagai titik simpul transportasi keluar masuk wilayah. Sesuai fungsinya terminal juga sebagai tempat parkir sementara (transit) penumpang atau kargo dari satu alat transportasi ke alat transportasi lainnya, sehingga dapat meningkatkan efisiensi perjalanan pengguna transportasi. Berdasarkan kebutuhan tersebut terminal juga harus mampu menampung, mengatur dan mengontrol melayani segala aktivitas yang terjadi akibat pergerakan kendaraan penumpang dan kargo dapat berjalan dengan lancar, tertib, tertib, aman dan nyaman. Dalam Kawasan Sarbagita sendiri terdapat beberapa letak terminal Seperti pada gambar 4.

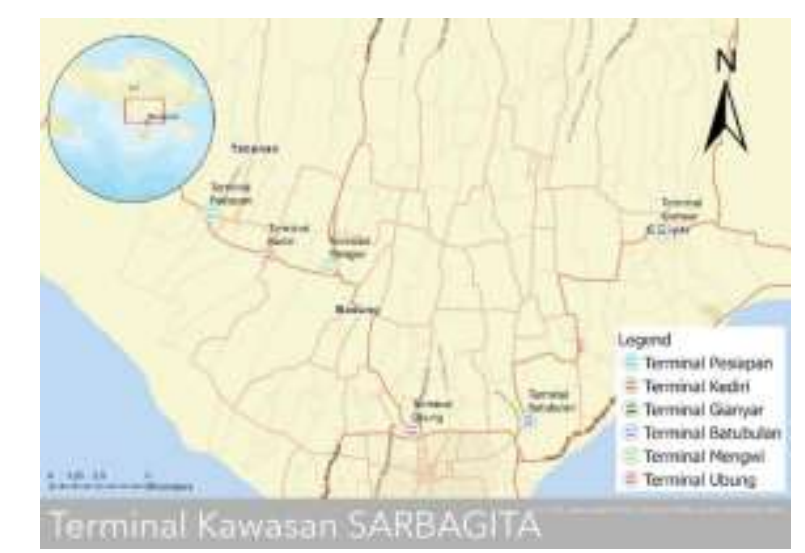

Gambar 4. Lokasi Terminal Kawasan Perkotaan SARBAGITA

(Sumber:Google Maps)

\section{Terminal Mengwi}

Terminal mengwi merupakan terminal Tipe A yang dikelola oleh kementerian Perhubungan dikelola oleh Balai Transportasi Darat (BPTD ) wilayah XII wilayah Bali dan Nusa Tenggara barat yang berlokasi di Mengwitani, Kec. Mengwi, Kabupaten Badung, Bali luasan terminal ini sekitar 15 hektar. Letak lokasi terminal Seperti pada gambar 5.

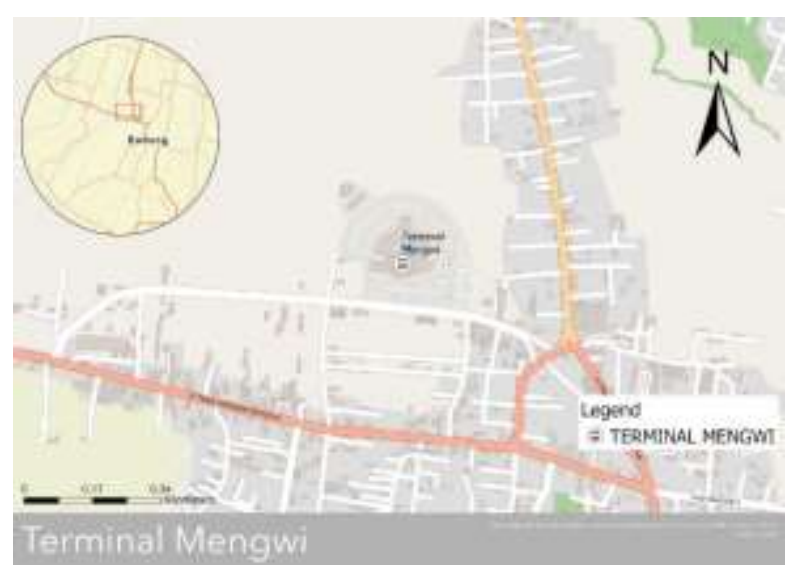

Gambar 5. Lokasi Terminal Mengwi

(Sumber: Google Maps) 
Letak lokasi terminal mengwi ini berada pada pertigaan simpul transportasi dari arah kedatangan pulau jawa, Tabanan dan dari Singaraja. Kedepan terminal mengwi akan dikembangkan oleh kementerian perhubungan menjadi terminal modern dan menjadikan terminal yang dapat digunakan untuk naik dan turun penumpang. Terminal mengwi juga akan di renovasi untuk menjadi daya Tarik pariwisata lokal maupun mancanegara. Sesuai dengan peraturan UU No 22 Tahun 2009 terminal ini merupakan Terminal Tipe A yang dikelola oleh Kementerian Perhubungan.

Terminal Tipe A disini berfungsi melayani kendaraan umum untuk angkutan antarkota dalam provinsi (AKAP), angkutan antar kota dalam provinsi (AKDP), angkutan perkotaan dan angkutan pedesaan termasuk bus trans Sarbagita. Terminal mengwi merupakan pintu masuk dari jalur darat ke wilayah Kawasan Sarbagita. Jam operasional terminal mengwi yaitu 24 jam dengan 3 shif penjagaan dari BPTD wilayah XII. Berikut merupakan fasilitas yang ada pada terminal mengwi seperti pada gambar 6.

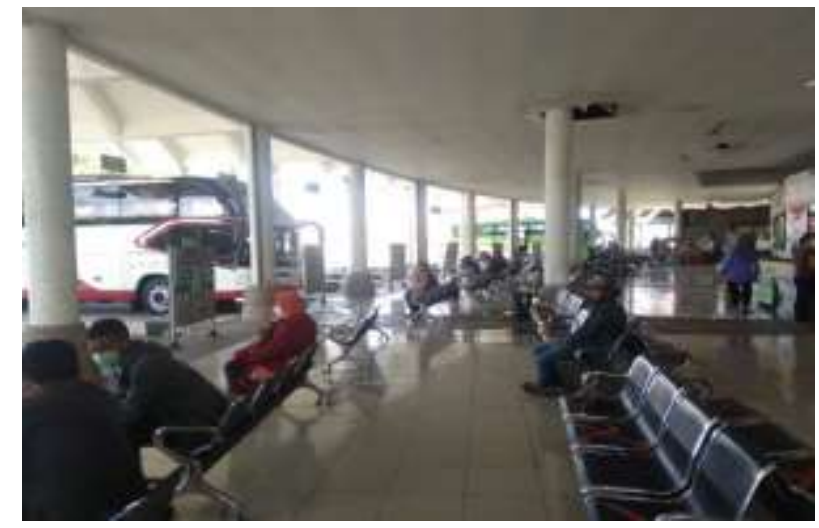

Gambar 6. Tempat Menunggu Bis di Terminal mengwi (Sumber : Dokumentasi Peneliti)

Saat ini rute yang ada pada terminal mengwi diantaranya :

a. Rute angkutan antarkota dalam provinsi Nusa Tenggara Barat (NTB)

b. Rute angkutan antarkota dalam provinsi Jawa Timur

c. Rute angkutan antarkota dalam provinsi Jawa Tengah dan D.I. Yogyakarta

d. Rute angkutan antarkota dalam provinsi Jawa Barat, DKI Jakarta, Banten dan Sumatera

e. Untuk Transportasi Kawasan SARBAGITA ada moda Teman Bus yang berhenti di terminal mengwi dengan rute Terminal Pesiapan - lapangan Parkir Kuta.

\section{Terminal Ubung}

Sejak beroperasionalnya terminal mengwi pada 23 oktober 2017, terminal ubung tidak melayani angkutan antar kota Provinsi. Sejak saat itu Terminal Ubung hanya melayani angkutan kota dan angkutan dalam perkotaan.

Sesuai dengan peraturan UU No 22 Tahun 2009 Terminal ubung merupakan terminal tipe B yang dikelola oleh Dinas Perhubungan Provinsi Bali. Terminal ubung yang merupakan pintu masuk kota Denpasar dari arah barat yang datang dari kabupaten Tabanan, Negara, Jembrana dan Pulau Jawa.

Lokasi terminal ubung terletak di jalan coktoaminoto, kelurahan Ubung, kecamatan Denpasar Utara, Kota Denpasar seperti pada gambar 7. 


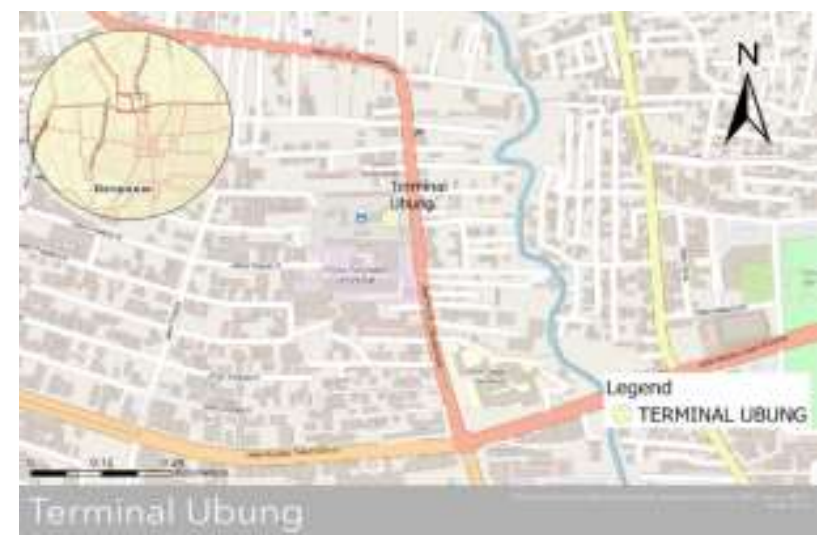

Gambar 7 lokasi terminal ubung Kota Denpasar

(Sumber: Google Maps)

Operasional di terminal ubung dari pukul 05.00 - 21.00 Wita. Pelaksana tugas dari dinas perhubungan provinsi Bali melakukan 3 shif jam kerja. Fasilitas yang ada pada terminal ruang tunggu seperti pada gambar 8 .

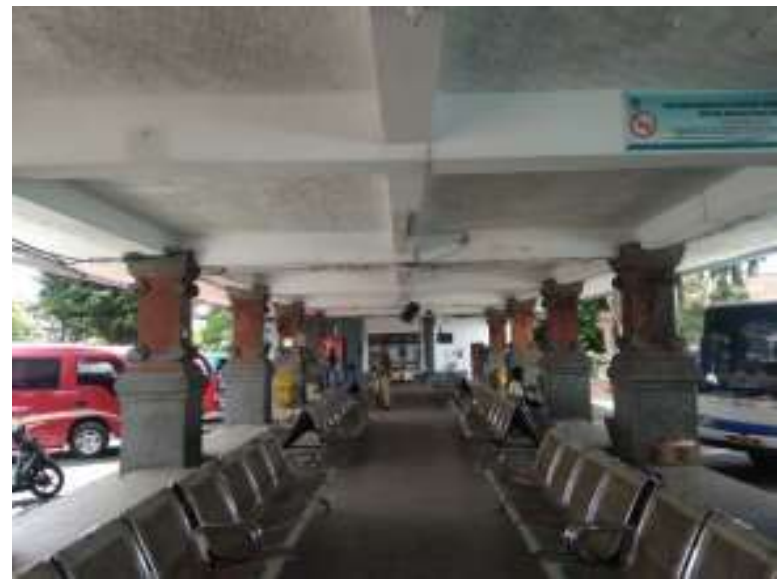

Gambar 8. ruang tunggu pemberangkatan Terminal Ubung (Sumber : Dokumentasi Peneliti)

Dalam operasionalnya terminal ubung melakukan Manajemen lalu lintas untuk menghindari penumpukan angkutan di dalam terminal di bedakan Pintu masuk terminal ubung melewati jalan cokroaminoto sedangkan pintu keluar melewati belakang dan keluar di jalan Gatot Subroto.

Berikut merupakan rute angkutan yang ada di terminal ubung :

1. Rute Angkutan Kota

a. Rute Terminal Ubung - Batubulan

b. Rute Terminal Ubung - Kreneng

c. Rute Terminal Ubung - Tegal

d. Rute Terminal Ubung - Sanglah 


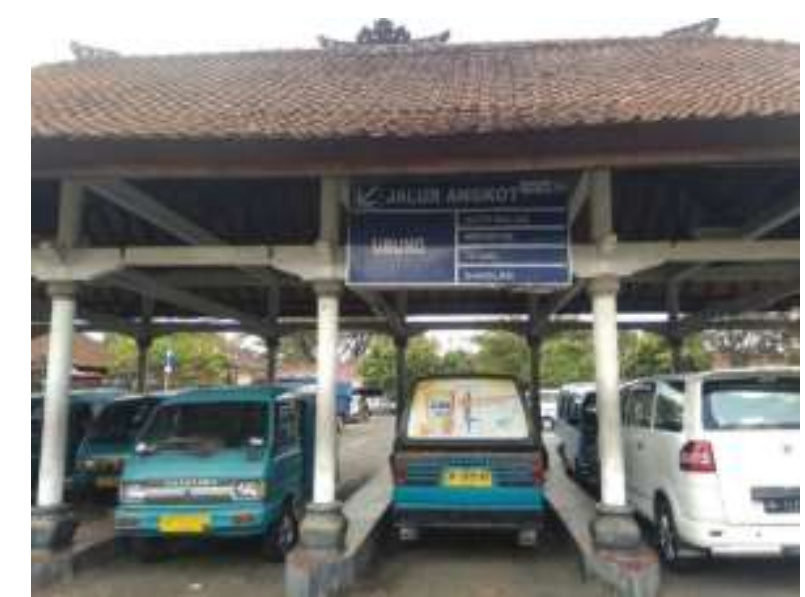

Gambar 9. Angkutan Kota di terminal Ubung (Sumber : Dokumentasi Peneliti)

Permasalahan dari rute angkutan kota tersebut untuk saat ini jumlah armadanya berkurang signifikan dikarenakan minimnya pengguna angkutan umum masyarakat denpasar yang lebih banyak memilih menggunakan moda kendaraan pribadi khususnya sepeda motor.

2. Rute Angkutan Isuzu/Microbus

a. Rute Terminal Ubung - Gilimanuk

b. Rute Terminal Ubung - Bedugul - Singaraja

c. Rute Terminal Ubung - Pupuan - Seririt

d. Rute Terminal Ubung - Bedugul -Munduk - Banyuatis

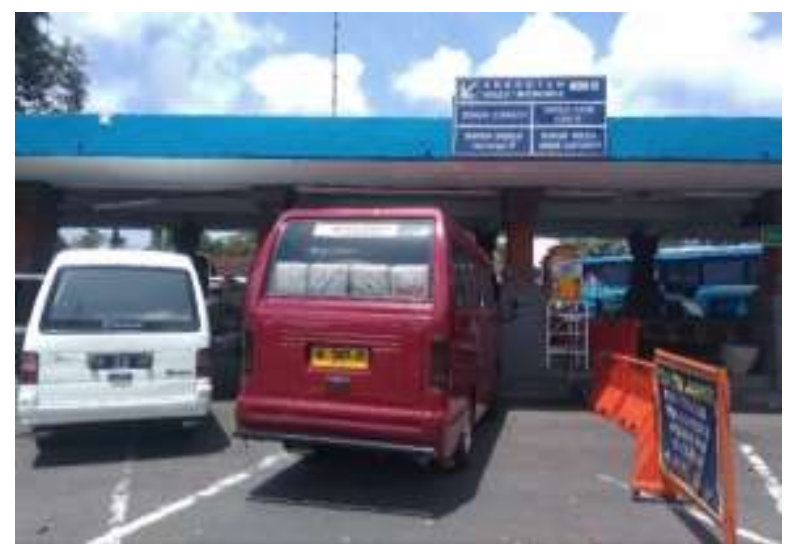

Gambar 10. Angkutan Izusu / Microbus Terminal Ubung (Sumber : Dokumentasi Peneliti)

Rute ini merupakan angkutan kota dalam provinsi yang beroperasi di terminal ubung.

\section{Trans Sarbagita}

Untuk bus Trans Sarbagita di terminal Ubung hanya ada 1 jalur rute dari terminal Ubung sampai ke Terminal Mengwi tidak melayani rute jalur lain.

Harga tiket bus Trans Sarbagita rute Ubung ke Mengwi adalah Rp 7.000,. jadwal keberangkatan Bus Trans Sarbagita dalam sehari berangkat Pulang pergi sekitar 5-6 kali dalam sehari. Jam operasional bus ini dari pukul $06.00-21.00$ Wita. Untuk tempat pemberhentian tidak ada tempat halte khusus, penumpang boleh berhenti di halte portabel dan sesuai keinginan. 


\section{Teman Bus}

Untuk Transportasi Kawasan SARBAGITA moda Teman Bus yang berhenti di terminal Ubung ada 3 rute yang saat ini beroperasi di terminal Ubung:

a. Rute Terminal Pesiapan - lapangan Parkir Kuta

b. Rute Terminal Ubung - Ubud (Monkey Forest)

c. Rute Terminal ubung - Sanur (Pantai Matahari Terbit)

Operasional dari teman bus ini dimulai pada pukul 05.00 - 19.00 wita. Untuk saat ini harga ditawarkan adalah Rp 3.000.

\section{Rute Bus Angkutan Antar Kota Dalam Propinsi (AKDP)}

a. Rute bus Angkutan Antar Kota Dalam Propinsi ke Gilimanuk

b. Rute jalur yang dilayani adalah Terminal Ubung - Tabanan - Negara Gilimanuk. dengan nama PO. Ariasa, Bahagia, Buana Raya, Fa. Darma dan Co, Megah, Putra Luhur, Sehati, Yusa Darmadi

c. Rute bus Angkutan Antar Kota Dalam Propinsi ke Singaraja

d. Rute jalur yang di lewati adalah Terminal Ubung - Pupuan - Seririt Singaraja. dengan nama PO Manis, Putra Jaya.

e. Jalur kedua yang dilayani adalah Semalapura - Ubung - Pupuan - Putih Dadap dengan nama PO Manis (Sandika)

f. Rute bus Angkutan Antar Kota Dalam Propinsi ke Padangbai

g. Gilimanuk - Ubung - Batubulan - Semalapura - Padangbai. Dengan nama PO Buana Raya, Gunung Harta, Lintas Samudera, Sri Wangi

\section{Terminal Pesiapan}

Terminal ini merupakan terminal Tipe $\mathrm{C}$ yang pengelolaannya dilakukan oleh Dinas Perhubungan Kabupaten Tabanan. Terminal Pesiapan adalah titik simpul transportasi kota Tabanan. Lokasi terminal terletak di Jl. Pulau Batam, Dauh Peken, Kec. Tabanan, Kabupaten Tabanan. Seperti pada gambar 11.

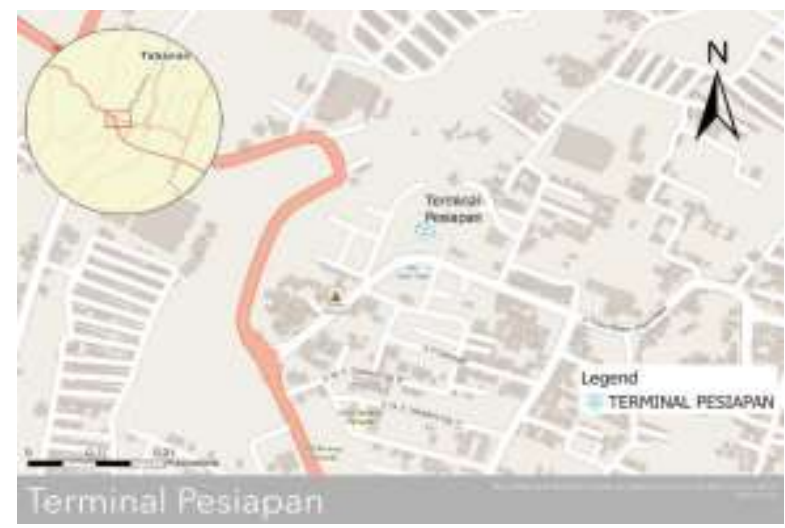

Gambar 11. Lokasi terminal Pesiapan (Sumber: Google Maps)

Operasional dari teman bus ini dimulai pada pukul 05.00 - 19.00 wita. Untuk saat ini harga ditawarkan adalah Rp 3.000.

6. Rute Bus Angkutan Antar Kota Dalam Propinsi (AKDP)

- Rute bus Angkutan Antar Kota Dalam Propinsi ke Gilimanuk 
Rute jalur yang dilayani adalah Terminal Ubung - Tabanan - Negara Gilimanuk. dengan nama PO. Ariasa, Bahagia, Buana Raya, Fa. Darma dan Co, Megah, Putra Luhur, Sehati, Yusa Darmadi

- Rute bus Angkutan Antar Kota Dalam Propinsi ke Singaraja

Rute jalur yang di lewati adalah Terminal Ubung - Pupuan - Seririt - Singaraja. dengan nama PO Manis, Putra Jaya.

Jalur kedua yang dilayani adalah Semalapura - Ubung - Pupuan - Putih Dadap dengan nama PO Manis (Sandika)

- Rute bus Angkutan Antar Kota Dalam Propinsi ke Padangbai

Gilimanuk - Ubung - Batubulan - Semalapura - Padangbai. Dengan nama PO Buana Raya, Gunung Harta, Lintas Samudera, Sri Wangi

\section{Terminal Pesiapan}

Terminal ini merupakan terminal Tipe $\mathrm{C}$ yang pengelolaannya dilakukan oleh Dinas Perhubungan Kabupaten Tabanan. Terminal Pesiapan adalah titik simpul transportasi kota Tabanan. Lokasi terminal terletak di Jl. Pulau Batam, Dauh Peken, Kec. Tabanan, Kabupaten Tabanan. Seperti pada gambar 11.

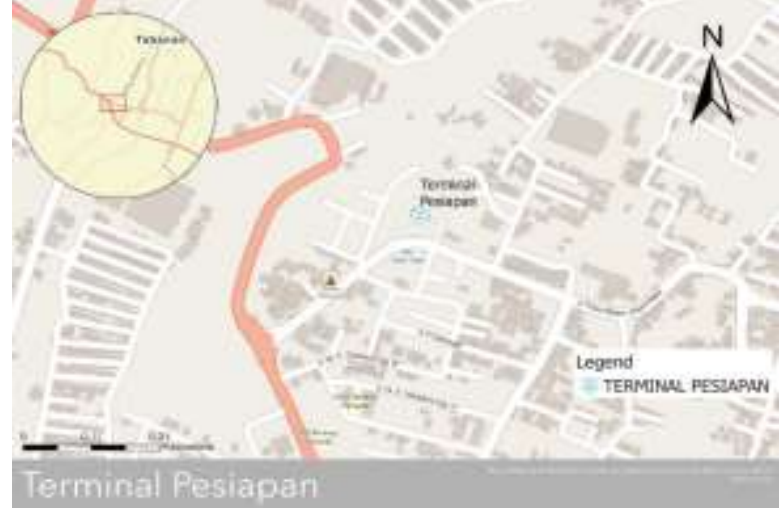

Gambar 11 lokasi terminal Pesiapan

(Sumber: Google Maps)

Jam operasional terminal pesiapan adalah pukul 06.00 - 19.00 Wita. Berikut adalah rute angkutan kota / angkutan desa yang beroperasi di terminal tabanan.

a. Terminal Pesiapan - Kediri

b. Terminal Pesiapan - Bongan

c. Terminal Pesiapan - Tuakilang

d. Terminal Pesiapan - Yeh Gangga

e. Terminal Pesiapan - Timpag

f. Terminal Pesiapan - Kerambitan

Untuk Transportasi Kawasan SARBAGITA ada moda Teman Bus yang memulai operasi dari Terminal Pesiapan - lapangan Parkir Kuta. Operasional teman bus dimulai pada pukul 05.00 - 19.00 Wita. Angkutan teman bus ini mengakomodir penumpang yang akan melakukan kegiatan menuju kota Denpasar dan kabupaten Badung.

Fasilitas yang ada pada terminal pesiapan Untuk tempat menunggu pemberangkatan ada di Gedung terminal seperti pada gambar 13. 


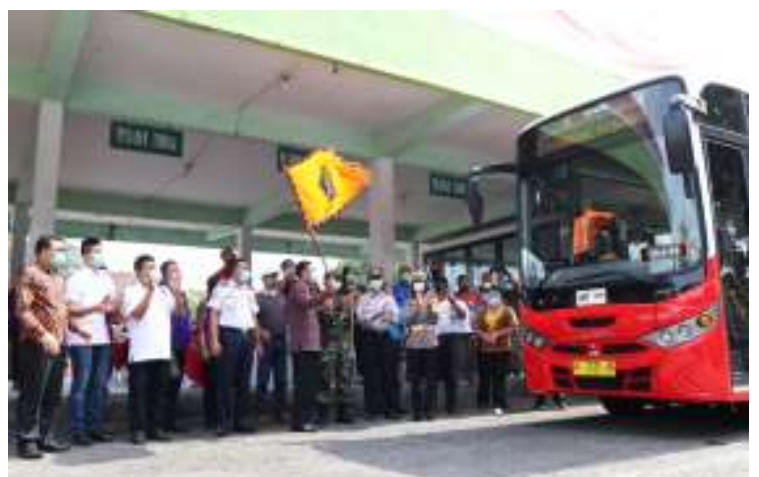

Gambar 13. Tempat menunggu terminal Pesiapan dan Operasional Teman Bus (Sumber : tabanankab.go.id)

\section{Terminal Kediri}

Terminal kediri yang terletak di Jl. Ngurah Rai No.78, Banjar Anyar, Kecamatan Kediri, Kabupaten Tabanan. Terminal kediri merupakan terminal tipe $\mathrm{C}$ yang melayani angkutan kota dan angkutan pedesaan. Operasional dari terminal kediri dari pukul $06.00-19.00$ Wita dengan petugas pelaksana penjaga dari dinas perhubungan kabupaten Tabanan. Untuk lebih jelas lokasi terminal kediri bisa dilihat pada gambar14.

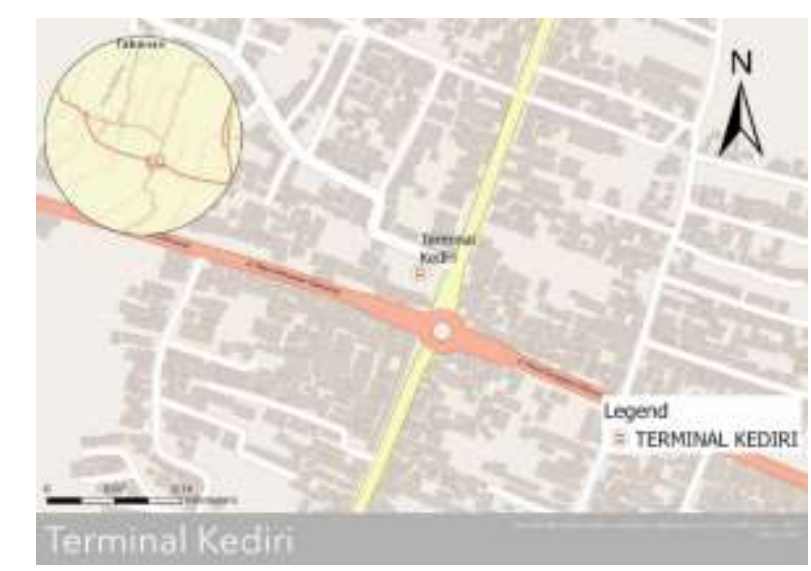

Gambar 14. Lokasi Terminal Kediri Tabanan (Sumber: Google Maps)

Berikut merupakan rute angkutan yang beroperasi di terminal kediri :

1. Rute angkutan kota Terminal Kediri - Tua Kilang.

2. Ruter angkutan kota Terminal kediri - Terminal Pesiapan.

3. Ruter angkutan kota Terminal kediri - Terminal Tanah Lot (sudah Tidak aktif)

4. Untuk Transportasi Kawasan SARBAGITA ada moda Teman Bus yang berhenti di terminal Kediri dengan rute Terminal Pesiapan - lapangan Parkir Kuta.

Gedung terminal berada pada tengah lokasi terminal dengan fasilitas untuk menunggu angkutan kota seperti pada gambar 15. 


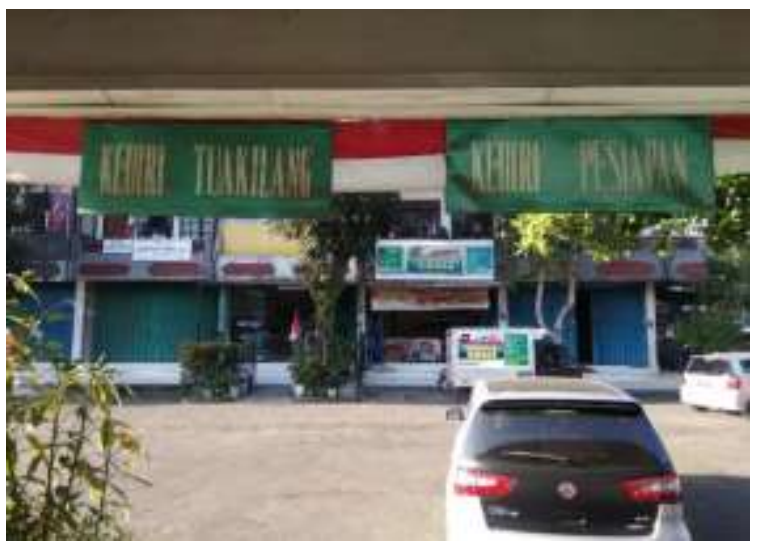

Gambar 15. Terminal kediri

(Sumber : Dokumentasi Peneliti)

\section{Terminal Batubulan}

Terminal batu bulan merupakan terminal tipe $C$ yang pengelolaan nya dilakukan oleh Dinas Perhubungan Kabupaten Gianyar. Terminal batubulan terletak di jalan raya batubulan, Kec. sukawati, Kabupaten Gianyar. Jam operasional terminal batu bulan adalah pukul 06.00 - 19.00 Wita. Seperti pada gambar 17 dan 18 .

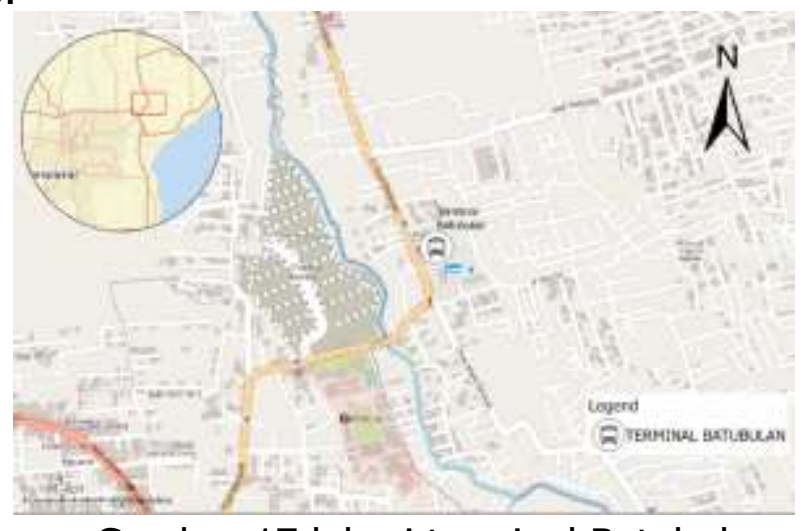

Gambar 17 lokasi terminal Batubulan

(Sumber:Google Maps)

Pada tahun 2019 jumlah angkutan yang beroperasi di terminal Batubulan sebanyak 75 angkutan dengan rute kecamatan, bus AKDP Singaraja, Amplapura, Bangli, dan Klungkung. Terminal batubulan merupakan pintu masuk kota Denpasar dari arah timur gianyar, bangle, klungkung, karang asem dan Provinsi Nusa Tenggara. Rute angkutan yang beroperasi diterminal batu bulan saat ini :

1. Rute Angkutan Kota

a. Terminal batubulan - Ubung

b. Terminal batubulan - Kreneng

2. Rute Angkutan Isuzu/Microbus

a. Terminal batubulan - Sukawati - Ubud.

b. Terminal batubulan - Semalapura - Padangbai.

c. Terminal batubulan - Semalapura - Amlapura.

3. Bus Trans Sarbagita

Bus transabagita beroperasi diterminal batu bulan yang memiliki 1 rute yaitu terminal batubulan - Nusa Dua. 
4. Untuk Transportasi Kawasan SARBAGITA ada moda Teman Bus yang berhenti di terminal Batubulan dengan rute Terminal Ubung - Ubud (Monkey Forest).

5. Rute Angkutan Antar Kota Dalam Propinsi (AKDP)

a. Rute Klungkung -Karangasem -Padangbai

b. Rute Bangli-Tabanan-Singaraja

\section{Terminal Gianyar}

Terminal Gianyar terletak di Jl. Anusapati No.80511, Gianyar, Kec. Gianyar, Kabupaten Gianyar. Pengelola terminal ini berada pada Dinas Perhubungan Kabupaten Gianyar. Terminal Gianyar untuk saat ini tidak beroperasi dikarenakan tidak adanya angkutan kota yang berhenti di terminal tersebut.

\section{SIMPULAN}

Untuk meningkatkan aksesibilitas angkutan umum perlu pembenahan lebih lanjut seperti waktu pemberangkatan harus jelas, angkutan umum tidak boleh menaik turunkan penumpang di tempat yang sudah ditentukan, pelayanan, keamanan dan kenyaman dari terminal di tingkatkan. Fasilitas terminal dikawasan SARBAGITA sudah menunjang aksesibilitas pengguna angkutan umum seperti ketersediaan ruang tunggu, waktu operasional terminal dan angkutan umum yang beroperasi. Fasilitas penunjang yang terdapat di kawasan Metropolitan Sarbagita sudah cukup memadai dalam segi kuantitas, namun secara kualitas harus ditingkatkan agar dapat menunjang aktivitas masyarakat pengguna angkutan umum. Alih fungsi terminal Gianyar menjadi sarana olah raga yang disebabkan oleh rendahnya minat masyarakat menggunakan angkutan umum yang kondisinya dinilai tidak efektif dan efisien.

\section{SARAN}

Pemerintah harus melakukan perbaikan pelayanan angkutan umum sehingga dapat meningkatkan minat masyarakat dalam menggunakan angkutan umum, dengan mengembangkan trayek angkutan umum yang sesuai dengan demand yang ada dan kemudahan aksesibilitas menuju rute pelayanan angkutan umum terdapat moda lanjutan. Melakukan identifikasi operasional angkutan umum dikawasan SARBAGITA dengan pembaharuan rute yang dilalui.

\section{DAFTAR PUSTAKA}

Dephub. (2009). Undang-undang Nomor 22 Tahun 2009 Tentang Lalu Lintas dan Angkutan Jalan. Departemen Perhubungan, Jakarta

Adisasmita, R. (2014). Manajemen Pembangunan Transportasi. Yogyakarta: Graha Ilmu.

Black, J \& Conroy, M,1977. Accessibility Measures and the Social Evaluation of Urban Structure,Environment and Planning A, 9, pp. 1013- 1031

Geurs, Karst T., \& Bert van Wee. (2004). Accessibility evaluation of land-use and transport strategies: review and research directions. Journal of Transport Geography. 12 (2): 127-140

Oktopianto, Y., Shofiah, S., Rokhman, F. A., \& Pangestu, K. (2021). Analisis Daerah Rawan Kecelakaan ( Black Site ) Dan Titik Rawan Kecelakaan ( Black 
Spot ) Provinsi Lampung. Borneo Engineering: Jurnal Teknik Sipil, 5(1), 4051. https://doi.org/10.35334/be.v5i1.1777

Peraturan Presiden Nomor 45 Tahun 2011 tentang Rencana Tata Ruang Denpasar, Badung, Gianyar, Tabanan.

Peraturan Presiden Nomor 51 Tahun 2014 tentang Perubahan Peraturan Presiden Nomor 45 Tahun 2011 tentang Rencana Tata Ruang Denpasar, Badung, Gianyar, dan Tabanan.

Peraturan Menteri Perhubungan Republik Indonesia Nomor PM 132. (2015). Tentang Penyelenggaraan Terminal Penumpang Angkutan Jalan.

Peraturan Menteri Perhubungan Republik Indonesia Nomor PM 40. (2015). Tentang Standar Pelayanan Penyelengaraan Terminal Penumpang Angkutan Jalan

Putu A. S. (2010). Analisis Karakteristik dan Kebutuhan Ruang Parkir Pada Pusat Perbelanjaan Di Kabupaten Badung. Universitas Udayana Denpasar.

Putra A. (2016). Studi evaluasi program Bus Trans Sarbagita Pemerintah Provinsi Bali, Kebijakan dan Manajemen Publik. Univeritas Airlangga. Surabaya.

Putrayasa A \& Maharani S. (2014). Efektifitas Bus Trans Sarbagita trayek Kota GWK dalam mengurangi kemacetan di Kota Denpasar dan Kabupaten Badung. Soshum Jurnal Sosial dan Humaniora 4(1)

Suthanaya, (2009). Analisis Aksesibilitas Penumpang Angkutan Umum Menuju Pusat Kota Denpasar Di Provinsi Bali. Ganeç SwaraEdisi Khusus 3(3)

Wulandari C \& Sudiana. (2018). Analisis Tingkat Efektivitas Trans Sarbagita sebagai Transportasi Publik di Provinsi Bali. E-Jurnal Ekonomi Pembangunan Universitas Udayana

Vukan R. Vuchic. 1981. Urban Pubic Transportation. New Jersey 